\title{
Ecological Landscape Planning and Design Strategies for Mangrove Communities (Hara Forests) in South-Pars Special Economic Energy Zone, Asalouyeh- Iran
}

\author{
Mohammad R. Masnavi ${ }^{1}$, Neda Amani ${ }^{2}$ \& Ali Ahmadzadeh ${ }^{3}$ \\ ${ }^{1}$ Faculty of Environment, Department of Environmental Design, University of Tehran, Tehran, Iran \\ ${ }^{2}$ Faculty of Environment, Department of Environmental Design, University of Tehran, Tehran, Iran \\ ${ }^{3}$ Pars Special Economic Energy Zone Org, Asalouyeh, Iran \\ Correspondence: Mohammad R. Masnavi, Faculty of Environment, Department of Environmental Design, \\ University of Tehran, Tehran, Iran. Tel: 98-21-611-131-789. E-mail: masnavim@ut.ac.ir
}

Received: October 30, 2015 Accepted: November 21, $2015 \quad$ Online Published: July 19, 2016

doi:10.5539/enrr.v6n3p44 URL: http://dx.doi.org/10.5539/enrr.v6n3p44

\begin{abstract}
Along with the strategic role of Asalouyeh region as an industrial zone in recent decades, there have been some growing problems regarding the ecosystems of the region due to the heavy activities such as petrochemical, industrial, transportation and related development in the area. The major region of Mangrove communities in the Persian Gulf that contains some unique ecotones has established a dynamic sustainable ecosystem integrating the relationship between sea and plateau ecosystems. It is also considered as a rich habitat for the creatures in flood and Ebb conditions. Therefore, taking in to account the increasing process of ecological destruction in the existing specific protected regions- especially the Mangrove communities, it is essential to study the structural relationships between landscape elements and patches in order to balance the ecological, social relationships as well as the environmental remediation based on the preservation of ecological structures. This study tries to examine the ecological role of Mangrove communities and their habitat to introduce the threatening factors in the "South Pars Special Economic Energy Zone" and then it suggests some strategies for ecological planning and design for protecting Mangrove communities in the area i.e. storm water management, protection and development of degraded habitats and phytoremediation, to create a framework for eco-tourism and Sustainable Development in the region.
\end{abstract}

Keywords: ecosystem, ecological landscape design, ecological disturbance, south Pars special economic energy zone Asalouyeh, mangrove communities, Hara forests ecosystem

\section{Introduction}

\subsection{Threatening Marginal Ecosystems by Active Industrial Areas}

Active industrial areas, by utilizing technology and natural resources, have had lots of economic benefits. But parallel to that, they have created human and environmental issues, which have led some disorders to the natural ecosystems and urban societies' health. The pollutions of upstream industries, petrochemical, oil and gas, widely around exploration, refining facilities and locally on the transportation lines of these materials in oil-rich provinces, are an inevitable outcome of rapid population growth and industrialization process and marine ecosystems threat.

" Pars Special Economic Energy Zone " (PSEEZ) is one of the most important subsidiary companies of the south oil-rich area that extends an area of 46000 ha from Bushehr province to the north of Khuzestan province (Figure 1). Persian Gulf pollutions caused by oil waste disposal, sedimentation, habitat destruction, wastewater and agricultural fertilizers discharges, excavation and increased heavy metals are the most important threatening factors of Persian Gulf ecosystems (Mickwitz et al., 2006).

\subsection{The Destruction of Mangrove Communities}

Mangroves communities are coastal ecosystems of Persian Gulf that has been emphasized as the most important foci of biodiversity, throughout the world. While are these forests now threatened with various human activities (Price et al., 1994). Location of the South Pars (Pars 1) along the Nayband Bay in Asalouyeh has caused 
destruction and removal of forests areas and has converted them to other uses; and the most important it has leaded to ecological fragmentation (Yavari et al., 2006) and has produced bidirectional contaminations in land and water of these sensitive vegetation habitats (Tomlinson, 1986).

\subsection{Rehabilitation of Ecosystems by landscape Ecology Principles}

According to the rise of industrialization and the destruction of the ecological structures, guidance and rehabilitation of ecosystems is urgent based on landscape ecology principles by considering human perception in design that results aesthetic reactions to the ecological quality of the landscape. And can provide possibility to coordinate structure and function of organizations in industrial context with ecological conditions and the natural systems of the environment by integrating of sustainable development and perceptual visual concepts.

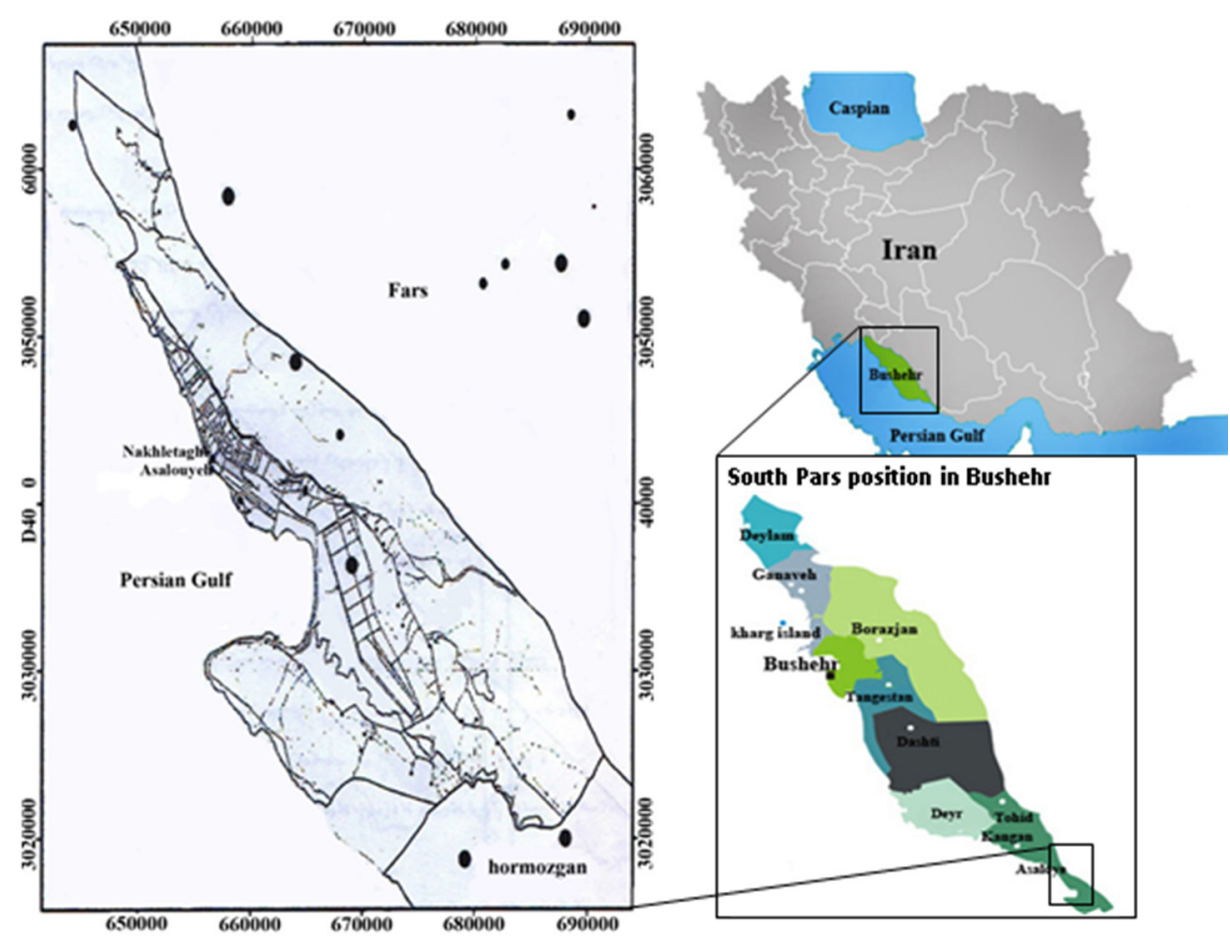

Figure1. Location of "Pars Special Economic Energy Zone 1" in Kangan city of Bushehr re-drawn based on 1982Geological maps and updated by GIS (Authors, 2014)

\section{Materials and Method}

This research conducted in three stages. Firstly the review of literature led to the identification and classification of major parameters influencing Mangrove communities' ecosystems and their life cycle; and their environmental planning and management. They are categorized as threats and opportunities to the Mangrove communities. In the next stage, the field observation was conducted in Asalouyeh- southern - Iran, to collect and rectify data about the Nayband bay Mangrove communities which is called Hara forests. The documentation of Nayband Hara forest has been done through preparing and mapping information. Several layers of information were prepared through GIS software such as vegetation covers, their location, their connectivity, distribution and fragmentation. Satellite images and GIS information then were used to prepare an overlaying method for analyzing data throughout the past five decades up to date. Finally the analyses of the prepared layers and transformation of Nayband Hara forest along with the landscape quality evaluation were used to develop ecological planning and design framework for the Nayband bay Hara forest.

\subsection{Managing Perspective to the Ecosystem}

Although in ecosystem management the maintaining of the all biodiversity and protected wide lands may be considered, according to Lackey, but have to remind that all these decisions benefits are for human. Managing approach has a revolutionary nature, and has proposed the ecological justice. From this approach, modern, linear, engineering and human oriented views are incorrect. He believes that the proponents of simple change of ecosystem management theory have two choices: 1) to prevent the ecosystem managing and declare that it is 
illegal, which is not practical or effective. 2) To accept the ecosystem management term within their framework (Lackey, 1995).

\subsubsection{Human Ecology Approach in Environmental Management}

Human ecology, is studying the relations between human beings and nature through a multidisciplinary approach, which has been considered from 1920 to examine the human factors in ecosystems. Human ecology approach has usage at different levels, from local to global, and support holistic studies. According to Baro the most ideal approach is the one that has a high adjusting capability and high clarity and its results must be tangible and visible for the public (Baro, 2002).

\subsubsection{Bio Region theory}

Bio Region is a distinguishable geographic area, which encompasses contiguous and self-maintained living systems with criteria such as watershed, ridge etc. It is considered for identification as the main areas of social harmony with nature, in the light of the ecology. According to this perspective, the human is a part of an ecosystem that is consisting: a) physical environment (climate, atmosphere, etc.), b) Soil as a separate substance in this physical environment, c) water, d) The vegetation consists of plants collections and, e) animals, which includes animals and community of human being. According to Don Flores, understanding the environmental changes over time in a region should begin by cognition of geology and climate history. However second base for life history of a region is beyond the environmental parameters, and includes the variety of the human cultures throughout the space and time (Yazdi \& Ebrahimi, 1998) Therefore, in this approach, "society" is the fundamental pillar, solidarity and continuous relation between human and the environment that leads to establish a balance for having social and natural potential. Sustainable development is the result of these events in which there is no conflict between individual and common benefits of human and nature (Sarefi, 2000; Yazdi \& Ebrahimi, 1998). This perspective therefore, within which the development of the local regional ecosystems combined with the potential of the area with emphasis on the rational utilization of resources, defines the use of technology in a way that the nature and human to be considered (Daneh kaar \& Jalali, 1996).

\subsection{Conceptual Common Ground between Visual and Ecological Landscape}

The definition of landscape ecology given by the International Association for Landscape Ecology shows its integrated approach: "Landscape ecology is the study of the interactions between the temporal and spatial aspects of a landscape and its flora, fauna and cultural components" (IALE, 2008; Gobster et al., 2007). Although ecology and aesthetics share many common aspects they have also kept their own research worlds with ecology relying mainly on the natural science traditions while aesthetics has held closely to humanistic research traditions. This remains one of the great challenges in developing indicators for both interests (Palang $\&$ Fry,2003). Many of the approaches to visual landscapes, especially those relating spatial aspects of landscapes to human preferences, have been paralleled by conceptual developments of space use and resource exploitation in landscape ecology, e.g. the concepts of habitat complementation and supplementation (Taylor et al., 1993) (Figure 2). Therefore, to recognize and understand the relationship between ecology and aesthetics on a conceptual level are of great importance in landscape planning and management (Fry et al., 2009).

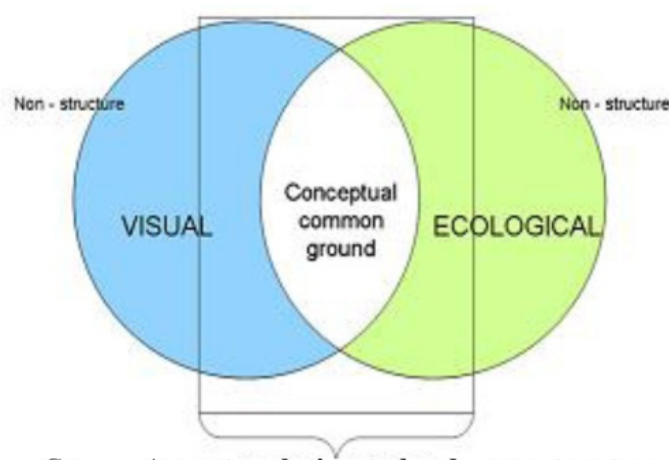

Scope: Aspects relating to landscape structure

Figure 2: the conceptual common ground between visual and ecological landscape character, related to landscape structure (Gobster et al., 2007) 
Visual character, these can be broadly divided into evolutionary and cultural preference theories (Appleton, 1975; Kaplan \& Kaplan, 1989). Evolutionary theories explain visual landscape preferences as shaped by our common evolutionary history, claiming that we respond positively to features that enhance survival and well-being. On the other hand preferences are explained as shaped by cultural and personal experiences, with beauty essentially being in the eye of the beholder (Meinig et al., 1976). This can make important contributions to landscape planning and management, and is our basis for the development of visual indicators from a conceptual approach (Fry et al., 2009).

Ecological function, according to Forman, this is related to three fundamental components of landscape: structure, function and change. Identifying the main structural elements in the landscape, and their relation to ecological processes are essential for our understanding of how landscape change will affect species and communities (Forman, 1995).

Understanding the relationships between structure and function also enables us to predict the ecological consequences of proposed spatial solution(s). A common classification of landscape structural elements is the Patch-Corridor-Matrix approach. The Patch-Corridor- Matrix model (PCM) is fundamental to landscape ecology theory, as it defines the spatial arrangement of elements in a landscape. This in turn directs the way we represent and measure landscape to assess how changes in landscape content and configuration affect ecological processes (Young, 2000). Although this model may be an oversimplification of landscapes and poorly represent mosaic landscapes, it has been validated through many studies in many contexts linking aspects of biodiversity to landscape pattern .Landscape metrics enable us to quantify the spatial processes of attrition, fragmentation, etc., thereby capturing numerical descriptors of change. These metrics have commonly been grouped as describing patch area, edges, shape, diversity and configuration (Fry et al., 2009).

\subsection{Landscape Ecological Aesthetics}

The scope of landscape ecology has always included man as a central actor in landscape change and its impact. Hence landscape ecology has always included a cultural perspective and taken account of what is important for people (Ibid).

The phenomenon that is included in human perception results in diversifying aesthetic experiment of landscape that in turn creates conceptual processes and their effective responses, in which presents perceptible patterns of landscape. But the measurement in which human being are as creatures, can percept landscapes, is a scope that is so called " perceptible realm ", since in this measurement human changes landscapes deliberately , and these changes affect the environmental processes (Gobster et al., 2007).

Definition of landscape therefore, has not bounded alone in lexical definitions that focused on restricted zone or the scenes of the land surface. It is although a vast array of biological and environmental processes. Hence ecological approach of landscape studies biological and geological to extent which results in creation of perceptional properties on the land surface and reflection qualities of landscapes that are subdivisions of environmental main processes. At the other hand evaluation of landscape aesthetic quality, is a science that includes both perceptional (mental factors) and experimental (visual factors) processes that leads in to aesthetic quality before human eyes (Terry, 2001)

So it could be deducted that visual aesthetic quality of landscape is derived from practical features which can be seen in a landscape in relation to mental processes (perceptual, cognitive and emotional) in a human observer.

From this point of view, aesthetic experiments term, Sceneries with intact environments included in inaccessible lands and far from human activity, have quite natural landscape patterns and benefited from high ecological quality. Patterns which present sceneries that depend on ecological aesthetic terms are affected from integral human care. It is reaction of sustainable elements and shows aesthetic experiments.

Hence to ecological evaluation of landscape it is needed to have a complementary relation between aesthetic pleasure and environmental health in landscape. So it is recommended to make use of strategies, which equal human values and ecological goals. There are points to start operation on making the effective action practical on landscape changes, and in relation to them, which are answers to aesthetic behavior (Gobster et al., 2007).

\subsection{Ecological Design: Comprehensive Application of the Art and Science of Environmental Design}

"Ecological Design" is the intersection between theory of the design and the environment. Ecological design is sensitive to the local conditions with precise cognition of the place, facilities and site constraints, and considers the topological and chorological flows of the region ecosystem. Thus this knowledge prepares the sense of the place in current design by understanding the changes over time and place. The intersection of this approach is similar to the sustainable development basic framework and is based on four principles "reuse, recycle, renovate 
and restoration" (Makhzoumi \& Pungetti,1999). Advocacy of ecological restoration and naturalistic landscapes has, at times, led to substantial controversy (Gobster \& Hull, 2000), though not exclusively because of visual appearance (Kaplan, 2007).

Thus, ecological design based on the patterns and rules of the nature, aims to reduce the pollution, to promote the principles of landscaping in order to prevent destructive changes in biophysical capacity of an ecosystem and to restore it as its primary ecology and native conditions of the area.

In other word, it is a combination of natural reconstruction and rehabilitation that aims to reduce negative environmental impacts such as soil amendment, refining polluted water and prepare a condition for improvement and boosting the environment.

\subsection{Mangroves Forest's Ecology}

Mangrove communities grow in tropical and subtropical regions, and grow only in tidal areas along the coasts, deltas, river estuary, coves, and sandy clay islands. Mangrove trees have respiratory roots that appear in different ways. Mangrove trees' seed spends a part of its growth stages on mother root, and therefore they are viviparo us

or pseudo viviparous (Tomlinson, 1986). These communities have an environment with ecotonic condition, which are in crossings of land and water and have been influenced by both environments. Thus they take advantage of the richness of the both environments while they are very sensitive because are threatened by both land and sea ecosystems (Tomlinson, 1986; Safyari, 2001; Majnoonian \& Miraab Zadeh, 2003). Upper and lower bound of Mangrove expansion are determined by temperature. Temperatures around $5^{\circ} \mathrm{C}$ and frostbite limit the mangrove distribution (Tomlinson, 1986). Tides are also effective in moderating temperature, as they cause the movement of the water bed by their continuous movement and in total water and sometimes toxic substances, which are derived from the decomposition of aquatics, are transferred to the water surface and through this, the temperature reduces (Hogarth, 2007). Although Mangrove forests have pure mass and little plants diversity, but they have a lot of animal diversity. Invertebrates, crustaceans, fish and fish-eating birds are highly significant in this habitat (Ebrahimi \& Riyahi, 2012).

Naybands' mangrove communities are only included tree species that named Avicennia marina and Mucronata Rhizophora (Figure 3 and Figure 4). Therefore in Iran mangrove forests are called Harraa. Herbaceous species are not counted as a part of the main species of mangrove (Daneh kaar \& Jalali, 1996).

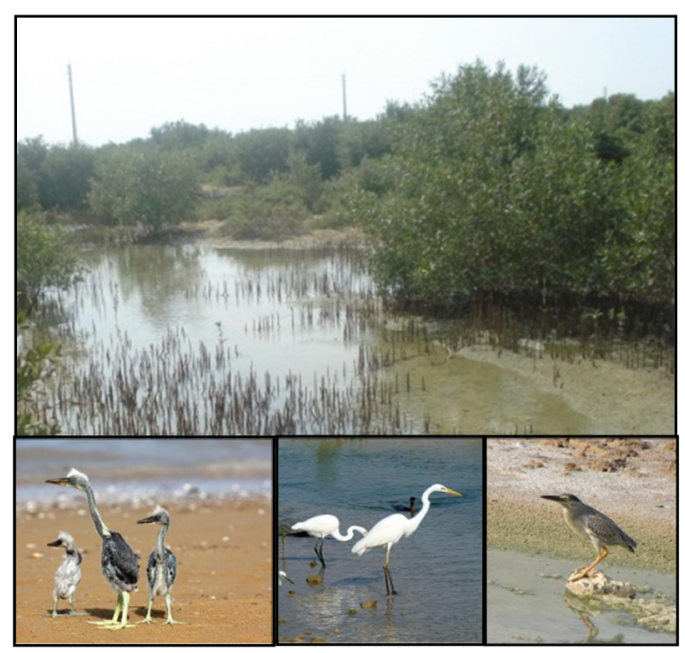

Figure 3. View of mangroves and some fish-eating birds (Authors, 2014)

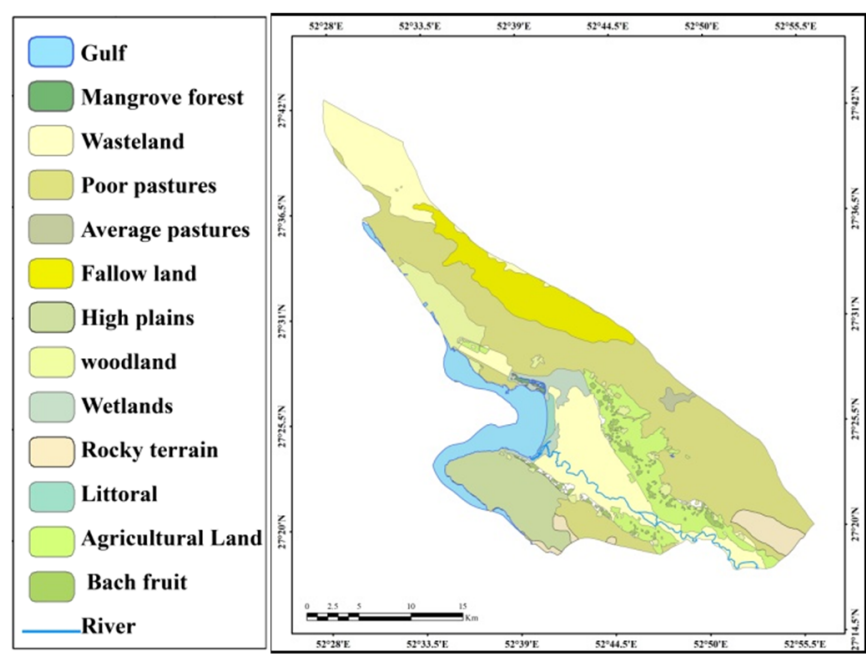

Figure 4. Classification of vegetation types and land use Pars Special Economic Energy Zone 1(Authors, 2014, based on Geological maps (1982) updated through GIS)

\subsubsection{Effective Factors in Mangrove Forests' Life}

Many factors are involved in the distribution and diversity of mangroves, such as flooding cycle, temperature, salinity, marine currents, wind, waves, storms, beach slope, substrate, soil and unsustainable substrate, deposition processes, fresh water entrance (Tomlinson, 1986). It should be noted that these cases indicates the necessity of preserving ecological processes (upstream and downstream) for mangrove communities' survival. 
2.5.2 The ecological importance of mangrove communities in protecting marine ecosystems are namely as followings:

- Tropical coastal ecosystems are important factors in preserving carbon balance (Sandilyan et al., 2012; Huang et al., 2003; Vane et al., 2009).

- Contributing to soil formation and protecting coastal communities against storms and leading shoreline to stability (FAO, 2007).

- Through the use and secretion salts and other solutes through the leaves are considered as filters for upland waters by turning seawater into freshwater (Odum et al., 1990).

- because of ecotonical conditions of mangrove communities streams, being rich in organic matter and nutrients from plant particles and also from the dry lands, they are valuable for many species of fishes. Hence they have a unique role in marine food chain (Ghosh et al., 2015; FAO, 2007; Safyari, 2001).

- High rate of production ( 2 ha /tons) during the year is such that protects the food cycle of sea and land (pelagic and benthic) and also carbon production and coastal fishing (Manson, 2005; Feller, 2002).

- Conserving biodiversity, which is included some endangered mammals, reptiles, amphibians and birds, and also through consolidation of coral reef, seaweed beds and sedimentation of suspended materials in the system to protect their roots ( Hendy et al., 2014).

\subsubsection{The Economic Importance of Mangrove Communities}

They can be summarized as followings:

- Fuel: the most important use of them is as cellulosic fuels, because Mangrove is the only specie in coastal lands that withstand and grow in extreme environmental conditions. Mangroves' wood heating value is estimated of 222 to $322 \mathrm{kcal}$ per $\mathrm{kg}$.

- Animal feeding: in the growing area of mangrove forests of Hormozgan province, branches pruning are common to feed animals, especially camels. Branches and leaves of mangrove trees in addition to being palatable for animals, they contain equivalent nutritional value like hay and barley( Amiri et al., 2001).

- Construction materials: the wood of mangrove trees is used as building materials because of strength and resistance to termites attack.

- Productive purposes: this habitat is important for Apiculture, producing pulp, providing tannins and charcoal, crafts and make suitable shelter for spawning and nursery for many marine economical species, such as some fish, shrimp and crab (Safyari, 2001). Nearly $80 \%$ of the economical aquatics animals of the Persian Gulf spend their spawning period in the mangrove forests (FAO, 2007).

- Sustainable tourism: the social aspects of the mangroves are important in terms of attractiveness of its unique aesthetic and recreational and educational (FAO, 2007). Of course before anything else, should be considered a program that is based on sustainable tourism and two principles of the protection of natural resources and cultural heritage.

\subsubsection{Threats and Limiting Factors of Mangrove Communities}

Mangrove forests have declined vastly since the expansion of industrial development and refining facilities in South Pars in the Persian Gulf area. So that currently 12000/5 to 13000 hectares of mangrove habitat, that $80 \%$ of it is located on the coast of Iran, has remained. While in 70 s decade 8500 ha of it was exclusively on the coast of Iran(Amiri et al., 2001). Existing data show that the population of some conserved species in the study area (such as Pazanan, ram, ewe and Jebeer Gazelle) have significantly endangered and due to few numbers couldn't be revived in any way (Masnavi \& Amani, 2014).

\subsection{Disturbances and Perturbations of Mangrove Habitat Affected by Asalouyeh Basin.}

Disturbance can cause to change structure or physical and simple transformation of this system. At last, its structure pattern changes. In this manner, ecosystem can embroil degradation which shows the sections destructed need restoration in which returns to before disturbance manner. We point to some of artificial (human made) factors are effective to ecology disconnection and reduce of natural power of this ecosystem (Figure 5). 


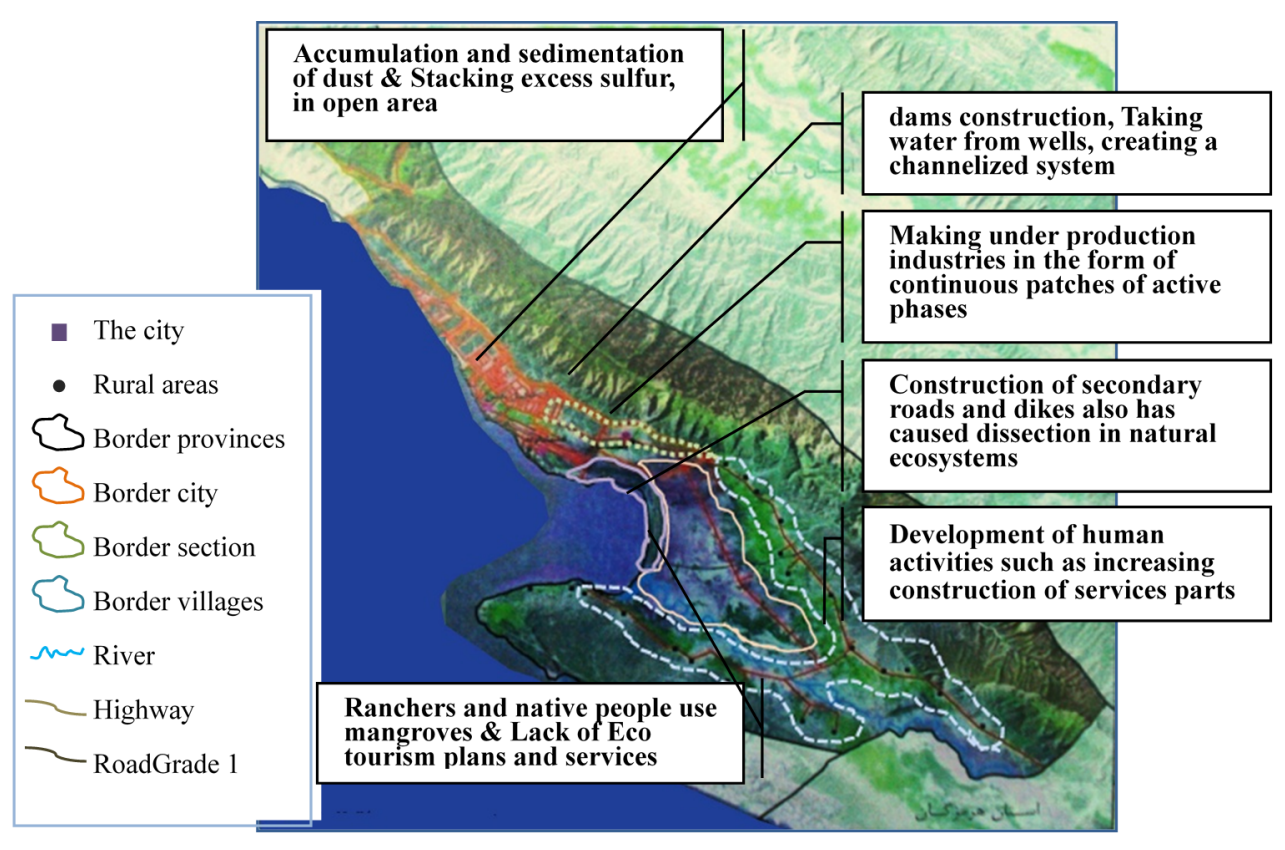

Figure 5. Disturbances and perturbations of mangrove habitat affected by Asalouyeh basin (own, 2014, based on Geological maps (1982) updated through GIS)

- Accumulation and sedimentation of dust remain like a cloud of the suspended particulate matter from the fuel gas industries, especially petrochemicals due to the mountains structure, petrochemical industry gathering in the west of the region, the effects of the moisture on temperature retention and dust heaviness, especially in the hot and humid months of the year (Amani, 2014).

- Stacking excess sulfur in open area that combines with particles from fuel gas flaring and other petrochemical facilities dusts. And after moisture absorption in the form of sulfuric acid, will cause pollution and destruction in the hydrologic system and native communities of the region.

- Groundwater contamination by heavy metals, cations and anions through various industrial processes as well as oil pollution from oil tankers traffic or marine accidents.

- Making under production industries in the form of continuous patches of active phases has led ecological connections, such as mountains, plains, and gulf (upstream and downstream) to fragmentation. In fact mangrove forests are in the form of an isolated patch between companies located in the region, and they have faced with reducing the ecological connections of (in the form of converting patch with connectivity body to the linking corridor) surrounding ecosystem (Amani, 2014).

- Construction of secondary roads and dikes also has caused dissection in natural ecosystems by cutting the ecological flow of the sea and mangrove communities. This dissection has led native patches to isolation and shrinkage and ultimately has caused reduction of the ecological capacity, as well as changing in process of the succession and balance in the native flora and fauna of the region, including: Disconnection of the tidal zone on both sides and the destruction of the mangrove habitats in the northern part (Torkianfar, 2007). Reduction of mangroves' root growth and increasing grass species of salted land that specify the water level during the tide. Increasing artificial wetlands that could be effective to change the balance between flora and fauna species in stagnant waters, particularly birds. Vehicles noise and air pollutions that are permitted to enter the area of the habitat without any limitation will result the water contamination, land degradation and ultimately will cause withering of these protected species.

- dams construction prevent the overflowing of the precipitation runoff from the specific flood of the desert areas flowing to the watershed and so this cause damage to the petrochemical Phases and companies and also cause the evaporation of such a large volumes of the fresh water resources basin.

- Taking water from wells, creating a channelized system and guiding surface water runoff despite providing a source of fresh water for the mangroves communities, result in decreasing of groundwater levels and thereby reducing the ecological capacity such as diversity in species associated with plateau and mountain in the region. 
This water deficit will cause an increase in the concentration of the pollution and will interfere in sediment transportation. Therefore reducing the surface flow will effect on increasing penetration and subsidence of water and hydrological disturbances also impact on bioaccumulation changes (Yavari \& Najmi Zadeh, 2006).

- Development of human activities such as increasing construction of services parts in the mangrove communities' habitats and use of seaside, which result in increasing of bacterial and chemical contamination because of the urban sewages (Torkianfar, 2007). Also this includes the development of agricultural, aquaculture, deformation of freshwater uses, disconnection of fresh water rivers, construction of shrimp ponds in the vicinity of mangrove forests and entering their wastewater in the sea, docks construction in timberlands (Guebas, 2000; Kairo, 2001; Huang, 2003).

- Ranchers and native people use mangroves, especially for grazing, are growing these trees annually about 30000 tones, According to the reports of Environment Agency, about 12000 tons of them are cropped for livestock (Amani et al., 2014).

- Lack of tourism plans and services: despite of travel and tourism attractions in this area, especially in the realm of protected habitats such as mangrove forests and their surrounding area.

- In destruction of mangrove forests due to natural factors, plant growth and development is threatened with series of aforementioned factors, along with environmental factors in region such as lack of nutrients, sediment in habitats that with changing in time and rate of daily accumulation. Increase of salinity that could be the result of droughts or changing in balance between precipitation and evaporation. And seasonal storms that uproot and destroy trees and plants, and finally inappropriate land morphology, have set Harra forests in an extremely sensitive and fragile conditions in the region (Odum et al., 1990), which in the lack of attention could cause an ecological crisis in the South Pars Special Zone.

\subsection{Conclusion of the Potential and Limitations of the Region}

Population growth, consideration the short-term benefits, lack of systematic management strategies and efficient techniques to restore and re-establish this ecosystem, unbalanced and inappropriate industrial units in the region are the most important threats to the region. There are deep shores with protected species, tourism and large financial resources in order to environmental care projects are the opportunities that should be considered to achieve an appropriate model for environmental management in the region. Of course mangroves' reaction due to defensive indicators against environmental changes such as the tension conditions is so that initially the plant growing will disturb and in severe level, the mangroves' seeding and flowers will impair.

\subsection{Environmental Management Aspect, Appropriate for Asalouyeh the Special Region}

Environmental management should seek the appropriate integration and balance between conservation and utilization of the biodiversity, that will be possible by estimating the national and regional needs, understanding the environmental impacts of gas and petrochemical industry's' functional process(Masnavi \& Amani 2014). Some functional aspects of environmental management, which should be accessible in the form of short term, medium term and long term program, include:

- The regulation of the type, amount and distribution of land uses in the region due to the principles of the Land use planning.

- Caring and refining the ecological capability of resources and improving the damaged areas.

- Maintaining and enhancing biodiversity and preventing the coastal ecosystems, coral reefs, Nayband Bay and ecological functions sets from pollution and degradation.

- Preventing water, soil, air and sound pollution, with new and advanced technology.

- Providing a basis for active participation by promoting the environmental culture in special complex zone and their subsidiaries, that is responsible for developing and managing the surrounding environment.

- Definition, explanation, measurement and assessment of indexes and criteria in order that to be able to determine environmental conditions of the region and act as required data for a system feedback.

\subsection{Asalouyeh Special Zone Guiding Strategies}

- Development of the environment by strengthening and planting plant species in the region and expanding green space (Incursive strategy and developing).

- Decentralization and involving non-governmental sector in the planning and management according to the environmental and man-made threats which are in the region. (Defensive strategy) 
- Environmental Management of Nayband region as the most important biological wealth of the region, by some methods including zoning and defining sensitive zones to prevent from more destruction and damage (Accommodating strategy).

- Coordinating affective elements on the regions' environmental management system in order to overcome internal weaknesses and minimizing internal weaknesses and minimizing weaknesses to overcome threats (Contingency strategy).

\section{Ecological Design Strategies Nayband Bays’ Mangrove Habitat Areas}

Ecological restoration is to restore ecosystem even closer to the functions and conditions of the pre-disturbance. However, because of the dynamic nature of natural ecosystems, it is very difficult to determine the situation of the pre-disturbance and the aim of the complete restoration of the landscape cannot be entirely realistic (Masnavi \& Amani 2014). In landscape ecology, the relationships between structures and components are more important than the individual components, these relations can be either vertical (into a spatial unit) or horizontal (between spatial units) (Figure 6).
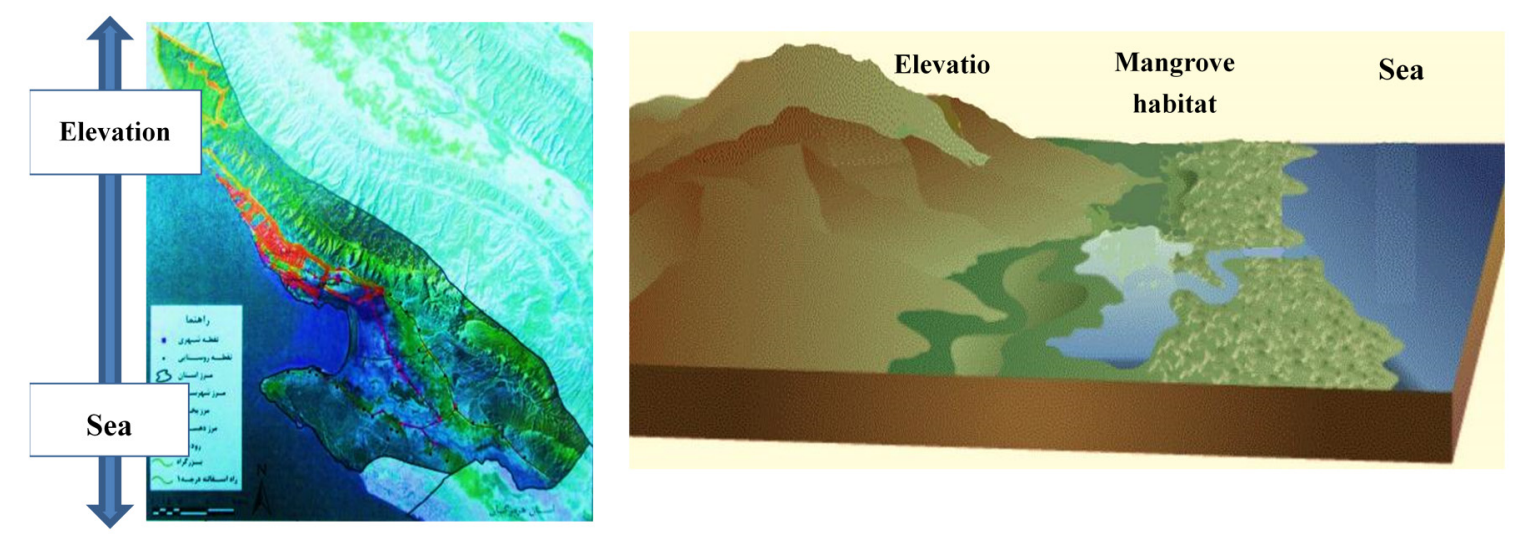

Figure 6. Schematic relation of height (upstream) to the area of mangrove communities in the Bay area epiglottis (downstream) (Authors, 2014)

Most coastal development planning involves mangrove restoration and management, and rehabilitation or restoration of mangrove ecosystems has been reviewed (Hai Ren et al., 2010). Here, according to the domain of human perception are presented strategies for planning and ecological design of mangrove communities and habitats of Nayband Bay area (and Table 1; Figure 7 ). 
Table 1. ecological design strategies of mangroves habitat in the Nayband bay (Authors, 2014)

Elevation
Regional flood
regime
management
Controlling
urban and
industrial
development

\section{Strategies}

Maintain the moisture balance in warm and humid areas is an important principle of specific climate protection in deserts (Yavari \& Najmi zadeh, 2006) Restoring the canalized system to conduct surface runoff from the mountains to provide required water and restoring biodiversity habitat that cause strengthening of ecological connectivity. B) Creating a permanent flow of fresh water for the mangrove communities.

A) restoring connecting corridors under construction areas with surrounded native ecosystems in order to create an urban ecological network

B) controlling the development of servicing sectors according to the domain of influence of the protected area C) native design and use of renewable energy, specifically solar energy to supply service units resources(Amani et al. 2014)

A) establish a comprehensive research based on preserve, restore, reform, development and utilization of forests

Creating

industries and

uses associated

with Harra

Research base by creating an advanced data system allow recognition of forest structure and analysis of ecological complex relations (Abdulkader \& Loughland, 2013), play a role in development and encouraging scientific and practical researches and creating guidelines for the use of mangrove forests' marginal industries for providing some parts of the research funding.

B) Creating a collaborative cultivation and educating the ways of planting ,protecting and harvesting of mangrove trees (Soemodihardjo et al., 1996)

C) Creating jobs for marginalized people in these forests by lopping of identified species

Mangrove forests of aesthetic value, as an integrated and homogeneous ecological

Planning and

designing of perspective, based on the close relationship between man and nature (Calatagan Park, 2011).

ecotourism Planning and designing tourism development based on the sustainable tourism principles and compatible with the sensitivity nature of the areas, so that provide alternative sources of income for local communities such as creating suitable environment station for survival, tourists tripping and making accommodation units and services in defined distance within the domain of influence of the mangrove habitat(Amani, 2014).

A) Natural regeneration as the best approach for the mangrove forests development 1) Rehabilitation and restoration of fragmented and isolated native patches and providing managed reproductive conditions 2) cleaning the invasive species on degraded lands 3) Selecting some areas for cultivation alongside the freshwater regime 4) silviculture compatible with mangrove forests at the interface between forest communities 5) creating mangroves' artificial habitat, along the shorelines and areas with growing capability 6)

Conservation and development of degraded habitat

Directing the tiding flow of the sea water controlling the weeds, pruning and caring of drainage and irrigation (Safyari, 2001). The major advantages of remote sensing data is monitoring of change periodically (Satapathy et al., 2007). We can to apply a multi-temporal and multi-scale approach based on historical maps and remote sensing data to detect changes in mangrove cover ( Ghosh et al., 2015).

B) Use of resistant plants to pollutants, especially to heavy metals

1) Development of green belt around pollution producing industries to separate contaminants and to trap atmospheric pollutants (Ebrahimi, 2012), 2) use of superabsorbent plants that have a high capacity of absorption and accumulation of heavy metals in their body by use of their resistance mechanisms and can be used for cleaning the contaminated soils. Also, pollutants accumulated, detoxicated and decomposed in some kinds of plants, depending on the level of planting and clean air without any pollutants emitted (ibid).

In the mechanism of this ecosystem, sea water enter evenly, freely from the bay mouth in all directions during the flood tide and cover the entire mangrove forest but by ancillary roads construction, water, just have possibility of pass and flow through the embedded vent that retreated to the last point before the ebb tide. Possibility of widespread penetration of sea water in computed location of under roads and built dikes with creating channels which can be effective in reducing the effects of landscape fragmentation and also protecting patches continuity of native mangroves 


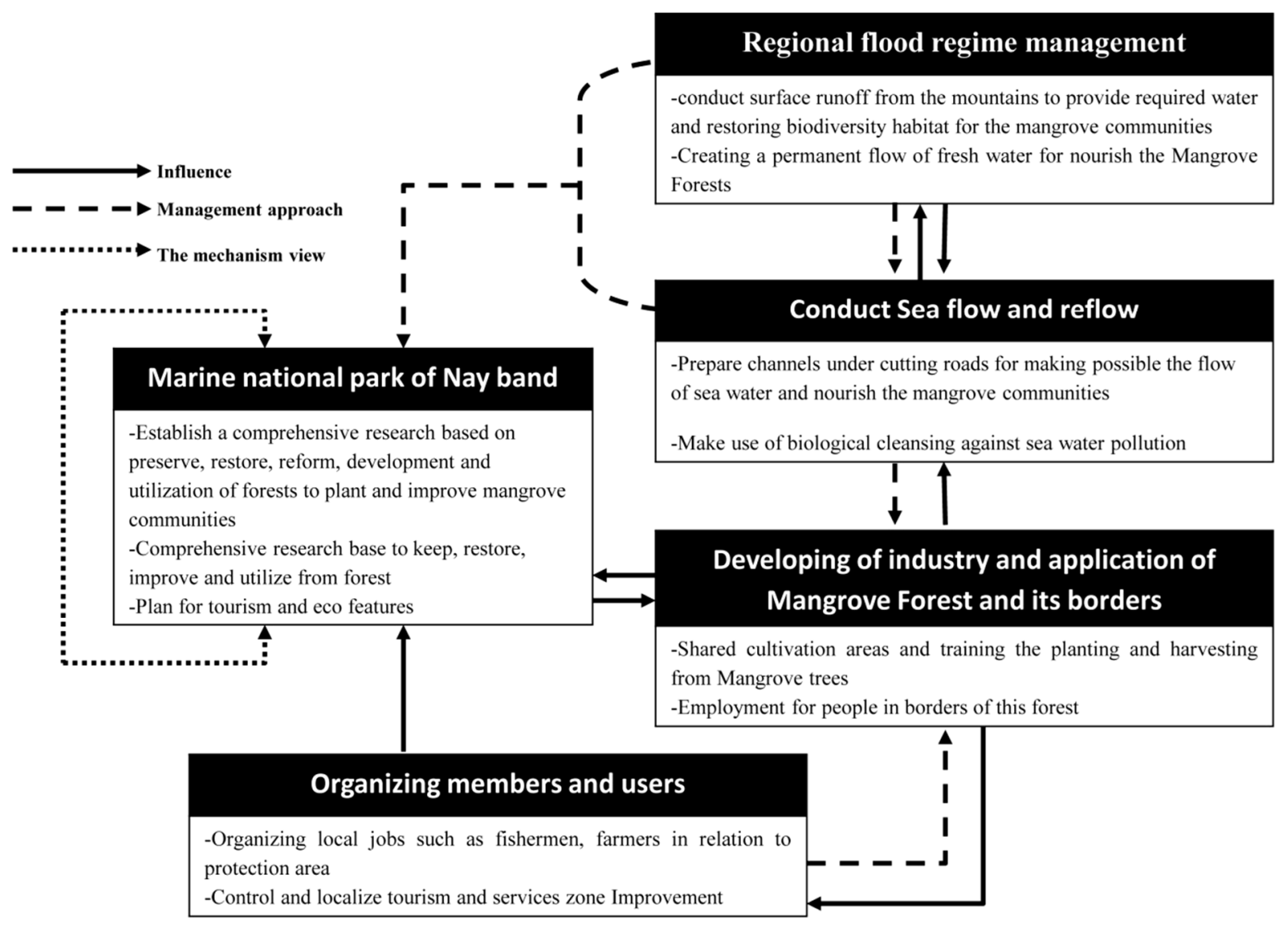

Figure 7. Communities surrounding the mangrove ecosystem conservation relations (Masnavi \& Amani, 2014)

Note. dependence on Nay band mangrove communities' protective strategies according to the level of impact on the surrounding ecosystem, the influence of larger scale cycle management approach and the importance of having a single point of view in relation to the surrounding ecosystem

\section{Conclusion}

It should be noted that the presence of associated systems is important, both in terms of vertical bank connections and also in time and location dimensions of resources' access (at different elevations during warm and cold seasons) as well as the connecting nature between these components by the weather. This is also an important issue in planning that is not considered yet. Water flow, causes sediment and vegetation growth in habitats, habitat and health reduction (Impaired migration, life cycle and migration), and disease increasing will be the result of each disturbance and increased pollution. Currently coastal areas around the world are at risk by the irregular exploitation of their natural resources. Pollution and conversion of coastal mangroves have grown so much that they has been faced with an uncertain future, so that many Mangrove communities have been wiped out and demolished during the development process. The conservation and sustainable management of the coastal zone therefore, is an important and fundamental objective to overcome the mangroves destruction in many countries. Overall, ecological capability has been declined in mangrove habitats area, which is related to the upstream and downstream connections (the upper mountain to the bay), located in Asalouyeh in the Nayband Bay. According to nested hierarchy utilization, restoration and conservation of the resources, regarding the spatial distribution and structural features of landscape are found with great importance. These have to be combined with vertical connection between them in terms of structure and function with the aim of the restoration of the natural landscape that has been contaminated, such as the use of engineering techniques and rehabilitation and revitalization according to the new standards. 


\section{Acknowledgments}

This paper is based on findings of the Masters Dissertation of the second author, and has been supported by the Research and Technology Management Section: N.I.O.C Pars Special Economic Energy Zone Organization (PSEEZ)., Asalouyeh, Iran.

\section{References}

Abdulkaderm, K., \& Loughland, R. (2013). Mangrove EcoPark ( pp. 30-31) Envir News, issue No. 21 , EED. Retrieved from http:/www.saudiaramco.com/en/home.html

Amani, N., Masnavi, M. R., \& Nabi, G. H. R. (2014). Environmental Design of Pars Special Economic Energy Zone - Asalouyeh (Pars 1). Unpublished Master's Thesis: Department of Environmental Design, University of Tehran

Amiri, S., \& Sadoogh, V. (2001). Appliance of plants branches from satellite data IRS to determine Nayband Mangrove forest surface in the vicinity to Oil facilities of Southern Pars. National conference of Iran's environment effects (pp. 38-43).

Baro, J. C. (2002). Principles and methods of environmental management. Kongreh publication, Tehran.

Calatagan Mangrove Forest Conservation Park. (2011). Marine Protected Area. Barangay Quilitisan. Calatagan, Batangas.

Dahdouh-Guebas, F., Mathenge, C., Kairo, J. G., \& Koedam, N. (2000). Utilization of mangrove wood products around Mida Creek (Kenya) amongst subsistence and commercial users. Economic Botany, 54, 513-527.

Daneh kaar, A., \& Jalali, S. (1996). Checking the Mangrove forests construction in Khamir and Gheshm(Qeshm) Zone (Hormozgan State) using transect, 35, 9-32

Ebrahimi. Z., \& Riyahi. A. (2012). Petroleum pollution in mangrove forests sediments from Qeshm Island and Khamir Port Persian Gulf, Iran.

FAO. (2007). The World's mangroves 1980-2005.

Feller, I. C. (2002). The role of herbivory by wood-boring insects in mangrove ecosystems in Belize. Oikos, 97, 1657-176.

Forman, R. T. T. (1995). Land Mosaics: The Ecology of Landscapes and Regions. Cambridge University Press, Cambridge

Fry, G., Tveit, M. S., Ode, A, \& Velarde, M. D. (2009). The ecology of visual landscapes: Exploring the conceptual common ground of visual and ecological landscape indicators. Ecological Indicators, 9, 933 947

Gobster P. H., Nassauer, J. I., Daniel, T. C., \& Fry, G. (2007). The shared landscape: what does aesthetics have to do with ecology. Landscape Ecol., 22, 959-972.

Gobster, P. H., \& Hull, R. B. (Eds.) (2000). Restoring Nature: Perspectives from the Social Sciences and Humanities. Island Press, Washington, DC.

Ghosh, A., Schmidt, S., Fickert, T., \& Nüsser, M. (2015). The Indian Sundarban mangrove forests: history, utilization, conservation strategies and local perception. Diversity, 7(2), 149-169.

Haines-Young, R. (2000). Sustainable development and sustainable landscapes: defining a new paradigm for landscape ecology. Fennia, 178(1), 7-14.

Hai Ren., Xiaoming Wu., Tianzhu Ning., Gu Huang., Jun Wang., Shuguang Jian., Hongfang Lu., (2010). Wetland changes and mangrove restoration planning in Shenzhen Bay, Southern China, International Consortium of Landscape and Ecological Engineering and Springer

Hendy, I. W., Michie, L., \& Taylor, B. W. (2014). Habitat creation and biodiversity maintenance in mangrove forests: teredinid bivalves as ecosystem engineers. PeerJ, 2, e591.

Hogarth, P. J. (2007). The biology of Mangroves and Sea grass (2nd ed.). Oxford University Press. New York.

Huang, L., Tan, Y., Song, X., Huang, X., Wang, H., Zhang, S., Dong, J., \& Chen, R. (2003). The status of the ecological environment and a proposed protection strategy in Sanya Bay, Hainan Island, China. Marine Pollution Bulletin., 47, 180-186.

Kairo, J. G., Dahdouh-Guebas, F., Bosire, J., \& Koedam, N. (2001). Restoration and management of mangrove systems - a lesson for and from the East African region. South African Journal of Botany, 67, 383-389. 
Kaplan, R. (2007). Employees' reactions to nearby nature at their workplace: The wild and the tame, Elsevier. Landscape and Urban Planning, 82(2007), 17-24.

Lackey R. T. (1995). Ecosystem management: implications for fisheries management. Renewable Resources Journal, 13(4), 11-13.

Majnoonian, H., \& Miraab, Z. (2003). Mangrove forest, protected coast zone. Environmental Protection Agency publication

Makhzoumi, J., \& Pungetti, G. (1999). Ecological landscape design and planning. E and FN spon, London, UK

Manson, F. J., Loneragan, N. R., Harch, B. D., Skilleter, G. A., \& Williams, L. (2005). A broad-scale analysis of links between coastal fisheries production and mangrove extent: a case-study for northeastern Australia. Fisheries Research, 74, 69-85.

Masnavi, M. R., \& Amani, N. (2014). Ecological Landscape Planning And Design Strategies For Mangrove Communities (Hara Forests) In South- Pars Special Economic Energy Zone, Asalouyeh - Iran. International Conference on Environmental Planning And Management (ICPM).

Masnavi, M. R., \& Amani, N. (2014). Industrial and Urban Development of South Pars Special Economic Energy Zone, Asalouyeh and strategies to reduce the environmental impact on marine protected area Nayband. First National Conference on Architecture, Urban Development and the Environment, University of martyr Mofateh. Hamedan.

Meinig, D. W. (1976). The beholding eye. Ten versions of the same scene. Landscape Architecture (January), $47-54$.

Mickwitz, P., Melanen, M., Rosenström, U., \& Seppälä, J. (2006). Regional eco-efficiency indicators-a participatory approach. Journal of Cleaner Production, 14(18), 1603-1611.

Odum, W. E., \& McIvor, C. C. (1990). Mangroves. In R. L. Myers, \& J. J. Ewel (Eds.), Ecosystems of Florida (pp. 517-548). University of Central Florida Press.

Palang, H., \& Fry, G. (Eds.) (2003). Landscape Interfaces: Cultural Heritage in Changing Landscapes (vol. 1). Kluwer Academic Publishers, Dordrecht.

Price, A. R. G., Downing, N., Fowler, S. W., Hardy, J. T., Le Tissier, M., Mathews, C. P., Wrathall, T. J. (1994). The 1991 Gulf War: Environmental Assessments of IUCN and Collaborators. IUCN, Gland, Switzerland in collaboration with WWF, IAEA and IOC.

Ren, H., Wu, X., Ning, T., Huang, G., Wang, J., Jian, S., \& Lu, H. (2011). Wetland changes and mangrove restoration planning in Shenzhen Bay, Southern China. Landscape and Ecological Engineering, 7(2), 241-250.

Safyari, S. (2002). Mangrove forests in World. Research Institute of Forests and Rangelands. Iran

Sandilyan. S., \& Kathiresan, K. (2012). Mangrove conservation: a global perspective. Springer Science+Business Media Dordrecht. Biodivers Conserv, 21, 3523-3542.

Sarefi, M. (2000). Principles of Regional Planning. PBO Publication, Tehran.

Satapathy, D. R., Krupadam, R. J., Kumar, L. P., \& Wate, S. R. (2007). The application of satellite data for the quantification of mangrove loss and coastal management in the Godavari estuary, East Coast of India. Environmental monitoring and assessment, 134(1-3), 453-469.

Soemodihardjo, S., Waroatmodgo, P., Mulia, F., \& Harahap, M. K. (1996). Restoration of Mangroves in Indonesia: A case study of Tembilaham, Sumatra. In C. D. Field, (Ed.), Restoration of Mangrove Eco systems. International society for mangrove ecosystem, Okinawa, Japan. pp 97-110

Taylor, P. D., Fahrig, L., Henein, K., \& Merriam, G. (1993). Connectivity is a vital element of landscape structure. Oikos. Springer Science+Business Media Dordrecht, 68, 571-573.

Terry C. D. (2001). Whither scenic beauty? Visual landscape quality assessment in the 21 st century. Springer Science+Business Media Dordrecht, 54, 267-281

Tomlinson, P. B. (1986). The botany of mangroves Cambridge. UK, Cambridge University Press.

Torkianfar F. (2007). Evaluation of environmental effects of Southern Pars Construction on Persian Gulf Shore. Masters dissertation, University of Tehran. 
Vane, C. H., Harrison, I., Kim, A. W., Moss-Haysa, V., Vickers, B. P., \& Hong K. (2009). Organic and metal contamination in surface mangrove sediments of South China. Marine Pollution Bulletin, 58, 134-144.

Yavari, A., \& Najmi Zadeh, S. (2006). Evaluation of environment outcomes. National conference of Iran's environment effects, 6, 66-51.

Yazdi, M., \& Ebrahimi, M. (1998). Rural improvement theories. Samt publication, Tehran.

\section{Copyrights}

Copyright for this article is retained by the author(s), with first publication rights granted to the journal.

This is an open-access article distributed under the terms and conditions of the Creative Commons Attribution license (http://creativecommons.org/licenses/by/3.0/). 